\title{
Acculturative Experiences of the English-Speaking Immigrants and Repatriates in Israel
}

\author{
Orly Kayam \\ Zinman College at the Wingate Institute \\ Netanya, Israel \\ Tijana Hirsch (Corresponding author) \\ Zinman College at the Wingate Institute \\ Netanya, Israel \\ E-mail: Tijana-h@wincol.ac.il
}

Received: August 20, 2013 Accepted: December 15, 2013 Published: January 21, 2014

doi:10.5296/iss.v2i1.4560

URL: http://dx.doi.org/10.5296/iss.v2i1.4560

\begin{abstract}
This study focused on the attitudes, motivations, and experiences of the immigrants and repatriates from English speaking countries in Israel $(n=232)$. Based on the welcoming national policy of ingathering of repatriates and the high regard for English language in Israel we predicted high motivational intensity in Hebrew language knowledge, English language maintenance and transmission to future generations, low anxiety levels in Hebrew language use, positive attitudes toward Israel and Israelis, and overall positive attitudes toward life in Israel. Our study supported these predictions and is based on the Acculturation Model and Interactive Acculturation Model (Berry, 1980, 1990, 1991, 1997; Bourhis et al., 1997), Common Ingroup Identity Model (Gaertner \& Dovidio, 2000), Similarity-Attraction Hypotesis (Byrne, 1971). Our findings point to a possible link between linguistic appreciation and healthier acculturation climate for both groups involved: the host and the immigrant. Educating the host community about the language of the immigrant may foster more inviting attitudes in the host community and in return support the integrative acculturative process of the incomers.
\end{abstract}

Keywords: integrative acculturation, repatriates, immigrants, multiculturalism, multilingualism, bilingual and bicultural development, successful immigration, intergroup processes 


\section{Introduction \& Literature Review}

The shared experiences of immigrant communities and their host societies are an important relationship that should be thoroughly explored by all societies housing different cultural, social, ethnic, and/or religious groups. The experiences of the newcomer and the host community create a climate within the country that permeates all aspects of shared living. It affects the safety, level of happiness, success, drive, and development of that society. Furthermore, it lays foundations for future generations' experiences in numerous arenas of social and physical wellbeing and vitality versus struggle and poverty.

Acculturation is a well-researched topic focusing on the factors affecting the ability to adapt and adjust to host or new settings and culture and the degree of the resulting adjustment. It is interested in examining immigrants' changes in attitude, values, behaviors, language, and cultural identification (Van Oudenhoven, Ward, \& Masgoret, 2006). There are many levels and approaches to acculturation research and several theoretical acculturation models. Early models of acculturation were unidimensional and represented on a linear, bipolar continuum. The later Balance model included biculturalism as the middle ground between assimilation and separation, and viewed heritage and host cultures as interdependent, while the multidimensional model views the two as independently influential in the acculturative process and the interplay between the two resulting in one of four modes of acculturation: assimilation (embracing the other at the cost of own), integration (maintaining own and embracing the other and the preferred model of acculturation, separation (maintaining own and rejecting other), and marginalization (neither keeping own, nor embracing the other) (Berry, 1980, 1990, 1991, 1997). It also assumes that acculturation processes take place independently in different domains (attitudes, values, behaviors, language, cultural identification).

In response to acculturation, immigrants go through a process of change according to Berry (1980) “...in at least 6 areas of psychological functioning (language, cognitive styles, personality, identity, attitudes, and acculturative stress). After some initial changes, the individual reaches a state of conflict at which point an adaptation strategy is reached. As individuals acculturate, a number of behaviors are modified together with attitudes, beliefs, and values. Berry argued that the four acculturation strategies are not discrete, static strategies; individuals may switch from one strategy to another; and the host culture may consist of several cultures rather than a single majority culture (Van Oudenhoven et al., 2006)." Further inquiry into the acculturative processes stimulated an interest into the role of the receiving society's expectations and attitudes and the resulting influence on the acculturative processes and strategies selected by the incoming immigrants (Bourhis et al., 1997; Berry, 2001). "Acculturation preferences (of individual immigrants and groups) may themselves be influenced by several factors. The prevailing condition in the society (e.g. prejudice and discrimination) and some external racial characteristics may affect the kind of acculturation mode ethnic minorities desire (Berry et al., 1989; Sam, 1992 as seen in Sam, 1995). "Bourhis et al. (1997) extended the models of acculturation with their Interactive Acculturation Model (IAM) by placing importance on the integration policies and orientations of the host communities and their effect on the immigrants' preferred orientations and strategies of 
acculturation. Therefor, the acculturation orientations of the host community impact the acculturation strategies of immigrants (or minorities) in different ways depending on what that orientation is and how it is received by the immigrants and their communities.

\subsection{Psychological Theories}

The examination of intergroup relationships has also been an area that attracted much social psychological research spanning many decades and yielding numerous hypotheses and theories. Of particular interest to current work are the Similarity-Attraction Hypothesis (Byrne, 1971) and the Common Ingroup Identity Model (Gaertner \& Dovidio, 2000). Similarity-Attraction Hypothesis postulates that people respond positively to those who are perceived as similar to themselves in terms of attitudes, values, and culture. Conversely, perceived differences will yield negative evaluation of the other. The Common Ingroup Identity Model quiet simply states that once a group of people is accepted as part of the ingroup, they will be treated as the ingroup members. The common identity is achieved through definitions of shared fate, common interests or goals, or belonging to a larger 'umbrella' membership. The subordinate group membership can be retained, but the superordinate group identity is the key to inclusion, equality, and acceptance.

\subsection{Acculturation and Immigrant Children}

Research (see Erikson, 1968; Phinney, 1990; Rosenthal \& Feldman, 1992b) shows that acculturation outcomes for children, due to their state of developmental change during the acculturation process, depends to a great degree on the parent-led moderation of experiences. Not surprisingly, parents affect the way children perceive different experiences and situations. The acculturation attitudes in immigrant children "...may be understood in part as a function of perceived parental attitudes (Sam, 1995)," although more research is needed in this area.

\subsection{Israel \& the English-speaking Immigrant Community}

Attitudes toward immigration and immigrants can and should be examined at different levels of society. The majority attitude towards immigration in Israel is positive, however, " ...the assessment of the host attitudes towards immigrants has to take into account variations within the majority society in the content, direction, and intensity of these attitudes (Berry, 1989)." Bar-Tzuri \& Hendels' (1992) study confirmed common values shared between Israeli citizens and the State of Israel in placing high regard and importance on the ingathering of Jewish people in the State of Israel ideologically speaking but that, however, when it came to allocation of state funds, immigrants (in this case, from the former Soviet Union) were viewed as 'deserving' little help.

Jasinkaja-Lahti, Liebkind, Horenczyk, and Schmitz (2003) examined three countries, among which was Israel, and which is "...defined as being composed of a kernel ancestral ethnic group as determined by birth and kinship, with subsequent categorizations made for so called "returning" ethnic migrants (82)" and that in such communities similarities between repatriates and the hosts are expected. It was found, however, that repatriates turned out to be culturally different, and ended up facing "...the same kinds of problems as other immigrants." 


\section{Mll Macrothink}

The English speaking community in Israel is viewed favorably in Israel. English as a language is highly regarded in Israel and it is very much sought after. Immigrants from English speaking countries immigrate to Israel voluntarily due to personal, preferential, and/or ideological reasons and not because of necessity or need, unlike many of the other immigrants or immigrant groups. "Anglos, "as English speakers in Israel are termed, are also perceived as needing less social help, as they come from countries with "stable" economies. In terms of The Instrumental Model of Group Conflict (Esses, Dovidio, Jackson, \& Armstrong, 2001), which states that two conditions lead to intergroup conflict: resource stress and presence of the distinct out-group, Anglophone immigrants may not be viewed as threats in social resource allocation due to their perceived economic stability.

Investigations into the Jewish and particularly Anglophone immigrant and host acculturative experiences in Israel are unique in terms of Common Ingroup Identity Model and Similarity Attraction hypothesis. As Jewish people, or as spouses married to Jewish people and who are raising their children in Israel, the common fate and membership is present right away, setting the stage for positive acculturative experiences. Furthermore, although perhaps culturally speaking the two groups may be different, the host community is known to perceive and evaluate all that is English positively, from language to people. This too, is setting a favorable acculturative climate for the immigrants from English speaking countries (for more on this see Kayam \& Hirsch, 2012).

In investigations of family language policies of the English speaking immigrant communities in Israel (see two studies by Kayam \& Hirsch, 2012) it was found that the English speaking immigrant community in Israel was highly proficient in Hebrew and it placed great importance on English language maintenance and transmission to their children. The level of FLP planning was split between high degrees of planning to no planning (or natural) evolution of FLP at home. Attitudes toward bilingualism and selections of preschools in terms of language were investigated. English speaking immigrants in Israel reported highly positive attitudes toward bilingualism and although a majority of the participants reported enrolling their children in Hebrew speaking preschools, a great majority of those who had the choice for bilingual English-Hebrew or English only preschools chose this as their option. In summary, the sample was integrated into Israeli society, highly proficient in Hebrew, favoring bilingualism, and concerned with maintaining and/or transferring English within the home to their children (Kayam \& Hirsch, 2012; Kayam \& Hirsch, 2012).

Based on previous findings, as well as our belief that the acculturative climate for English speaking immigrants in Israel is positive and mostly inviting, we believe that we will find this community to report positive experience which stem from positive acculturative experiences and well integrated repatriate/immigrant community within Israel.

We expect to find:

1. High motivational intensity towards Hebrew language knowledge for themselves and future generations (their children)

2. High motivational intensity toward English language maintenance and transmission to 
their children

3. The anxiety levels of Hebrew language use will be low

4. Attitudes toward Israelis and the Israeli culture will be positive

5. Intent to settle permanently in Israel as well as the satisfaction level will be high

\section{Methods}

232 English-speaking immigrants were surveyed using the questionnaire created for the purpose of the current study. Participants invited for participation included those who have (themselves or their partner) immigrated to Israel from an English-speaking country, or who spent a considerable amount of time living in an English speaking country prior to their return to Israel. Furthermore, only those participants who have children were invited to participate in order to investigate different processes taking place within the family in terms of family language policy (FLP) post immigration. All responses were collected online using the free of charge google documents tool. Participation in the study was anonymous and voluntary. No incentives were given for participation in our study. The purpose of the study was communicated on the first page of the document. Participants were reached through different immigrant representing organizations' websites, e-mail lists, social media channels such as the Facebook, and others. (For a detailed description of our approach see Kayam \& Hirsch, 2012). The questionnaire included demographical questions, language planning questions, experiences, practices, outcomes, and others.

The current study is descriptive in nature. The purpose of the study is to explore the experiences of this immigrant community within Israel overall, and specifically as tied to language use/knowledge.

\subsection{Questionnaire}

The tool was created for the purpose of this study. It included adapted items from the Attitude/Motivation Test Battery on Motivational Intensity toward Hebrew language learning/knowledge, Attitudes toward Hebrew, Hebrew Use Anxiety, Attitudes toward Israelis, and Integrative and Instrumental Orientations (Gardner, 2004). We also included a measure on properties of language as used by Lewin (1987), as well as three items on overall immigrant experiences.

\section{Findings}

\subsection{Motivational Intensity}

Motivational intensity toward Hebrew knowledge among our sample of English speaking immigrants in Israel was found to be high.

To a statement "I want to know Hebrew so well that it will become natural to me" an overwhelming $83 \%$ of the participants selected a rating of 4 or 5 corresponding to agree and strongly agree respectively.

In response to the statement "My desire to know Hebrew " $77 \%$ of the participants selected a 
response corresponding to strong or very strong, while $4 \%$ of the participants selected the response weak or very weak.

To a statement "I am losing any desire I ever had to know Hebrew" $78 \%$ of the participants disagreed.

To a statement " When I have a problem understanding something in Hebrew, I always $\operatorname{ask}^{\text {" }} 60 \%$ of the respondents chose the rating of 4 or 5 corresponding to responses of agree and strongly agree respectively. Eleven per cent of the respondents disagreed with the statement, choosing a rating of 1 or 2 . A little over half of the participants disagreed with the statement: "I tend to give up and not pay attention when I don't understand something in a Hebrew setting," with 54\%, while 19\% indicated that this is indeed the case.

About equal number of participants agreed, disagreed, and were neutral in their response to the statement: "I keep up to date with Hebrew by working on it almost every day," with $30 \%$, $35 \%$, and $27 \%$ respectively.

When asked to indicate their level of agreement with the statement "I can't be bothered trying to understand the more complex aspects of Hebrew, “60\% of the participants disagreed with the statement. Eighteen per cent agreed, and $13 \%$ selected a neutral position.

In response to our participants' motivational intensity toward Hebrew language knowledge for their children, $86 \%$ of the respondents selected ratings strong or very strong, while only $5 \%$ selected a rating of weak or very weak.

In regards to the our participants' motivational intensity toward English language knowledge the response was similar, with $87 \%$ of the participants selecting strong or very strong and $2 \%$ selecting a rating of 3 on a 5 point scale.

\subsection{Attitude \& Anxiety toward Hebrew}

In response to the statement "I hate Hebrew" $77 \%$ of the participants selected a disagree or strongly disagree rating. Four per cent agreed.

Fifty seven percent of the participants indicated high level of comfort while speaking Hebrew, while $22 \%$ of the participants reported feeling anxious while speaking Hebrew.

\subsection{Integrative \& Instrumental Orientations}

Integrative orientation was found to be high among our participants. Eighty four per cent of the participants agreed or strongly agreed with the statement "Knowing Hebrew is important because it will enable me to better understand and appreciate the Israeli way of life."

In looking at responses to instrumental orientation measures, knowledge of Hebrew was selected as important as it will make one more educated by $52 \%$ of the participants and respect that will be gained from others by $54 \%$ of the participants. However, $78 \%$ of the participants saw Hebrew knowledge as important as it is useful in getting a good job. 


\subsection{Attitude toward Israelis}

Fifty eight per cent of the participants indicated having many Israeli friends, while 16\% indicated having no Israeli friends. Thirty two per cent of the participants indicated a desire for knowing more native Hebrew speakers, $15 \%$ were not interested. Forty three per cent of the participants found Israelis to be sociable and kind, 13\% disagreed with the statement, while $37 \%$ were in the middle of the spectrum. To the statement "The more I get to know Israelis the more I dislike them," $66 \%$ disagreed with the statement, $20 \%$ were undecided, and $6 \%$ agreed.

\subsection{Properties of Languages}

Participants were asked to indicate in which of the following characteristics they thought English was stronger than Hebrew: beautiful, promotes a progressive outlook, encourages ethnocentricism, difficult to learn as a second language, easier to present scientific facts, easier to present moral/religious ideas, has a flourishing literature, prestigious, logical, rich vocabulary (the right word for any concept). In all cases very few, if any, selections were made.

\subsection{Overall Immigrant Experience}

Our sample of English speaking immigrants reported feeling settled and highly satisfied with their life in Israel. Sixty six per cent would not leave Israel today it they could*, and only $6 \%$ would. (*Could is used loosely, in terms applicable to each participant and situation as they individually understand and experience it). Only $13 \%$ of the participants do not plan to stay in Israel permanently, $71 \%$ plan to stay permanently, and $10 \%$ are undecided. To a statement "I am quite happy living in Israel at the moment" 63\% agreed, while 13\% did not.

\section{Discussion}

We are aware that the acculturation orientations and strategies of the English speaking community in Israel are speculative until measured directly. Based on the positive overall attitude of the Israeli society toward ingathering of repatriates and specifically, the favorable (if not desirable) attitudes toward the English language, and by extension the English speaker, the climate is favorable for integrative acculturation attitudes from both sides. English speaking repatriates and immigrants in Israel experience a positive and welcoming attitude from the host community and that in response, they feel motivated, appreciative, and satisfied with their lives in Israel. This interplay between the two groups is explained and supported by the Interactive Acculturation Model (IAM) as described earlier in this paper. The status of English within Israel, and by extension of it's speakers creates a favorable climate for maintenance of the perceptions of similarity and togetherness as explained by the Common Ingroup Identity Model and the Similarity-Attraction Hypothesis and at the same time provides an explanation for the discords that develop with repatriates from other cultural and linguistic backgrounds in Israel, such as for example, the Russian speaking repatriates (see Zemach \& Wiesel, 1996; Ilatov \& Shamai, 1996). Through our study we learned that English speaking immigrants and repatriates in Israel feel well and welcome. They express positive attitudes toward Israel and Israelis and plan on settling in Israel permanently. They are 
satisfied with their lives in Israel and proud of their Anglophone background. We believe that this welcoming climate toward a language and by extension, its people, created a healthy climate for embracing of the new and maintaining of the native. This is supported by high motivational intensity toward English language maintenance and transmission to future generations (their children) and by high ratings of motivational intensity toward Hebrew language knowledge for both, themselves and their children, as well as favorable ratings of the Israeli culture and Israelis. Our sample of English speaking immigrants/repatriates in Israel reported not viewing English as superior to Hebrew in any of the categories. The belief that it is easier to present scientific facts in English or that English is more prestigious as reported by Lewin (1987), Nadel \& Fishman (1977), Hofman (1974) was not reported by our sample. By examining language-centered immigrant community of the language that is highly regarded and sought after in Israel we have found that the bearers of that language open up to and embrace the language and culture which surrounds them, even though, the English speaking community in Israel could function quiet successfully without the knowledge of Hebrew. They seem to embrace Hebrew on all levels, through attitudes, beliefs, and in practice. Our study supports the findings that point to advantages and importance of policies supporting and promoting other languages and multilingual policies as stimulants for healthy acculturation experiences for both host communities and the immigrants, repatriates or not. We encourage further and deeper probing into this link and urge developments of projects that promote appreciation of other languages and their contributions. Perhaps, if the rich contributions of the Russian language and literature, for example, were taught to the host community in Israel, the acculturative climate would be more fertile for both groups to integrate and truly embrace each other.

\section{Acknowledgements}

We would like to thank our participants for taking the time to answer our questions. Thank you to the English-speaking immigrant organizations in Israel who have helped us reach the English speaking immigrants throughout Israel. In particular, we would like to thank Mr. Dorron Klein and Telfed for helping us reach the South African community in Israel and get in touch with other organizations serving the English speaking communities. Thank you to Aviva Zeev for all your help with data analysis and to Chaya Zipori for her help with editing of this paper. We appreciate everyone's involvement.

\section{References}

Bar-Tzuri, R., \& Hendels, Y. (1992). Attitudes toward Soviet immigrants: An analysis of survey data. Kalkalah Ve avodah, 8, 48-52 (In Hebrew).

Berry, J. W. (1980). Acculturation as varieties of adaptation. In A. M. Padilla (Ed.), Acculturation: Theory, models and some new findings (pp. 9-25). Boulder, CO: Westview.

Berry, J. W. (1990). The role of psychology in ethnic studies. Canadian Ethnic Studies, 12, 8-21.

Berry, J. W. (1991). Understanding and managing multiculturalism: Some possible implications of research in Canada. Psychology and Developing Societies, 3, 17-49. 
http://dx.doi.org/10.1177/097133369100300103

Berry, J. W. (1997). Immigration, acculturation and adaptation. Applied Psychology: An International Review, 46, 5-34.

Berry, J. W., Kim, U., Power, S., Young, M., \& Bujaki, M. (1989). Acculturation attitudes in plural societies. Applied Psychology: An International Review, 38, 185-206. http://dx.doi.org/10.1111/j.1464-0597.1989.tb01208.x

Bourhis, R. Y., Moise, L. C., Perreault, S., \& Senecal, S. (1997). Towards an interactive acculturation model: A social-psychological approach. International Journal of Psychology, 32(6), 369-386. http://dx.doi.org/10.1080/002075997400629

Byrne, B. (1971). The Attraction Paradigm. New York: Academic Press.

Erikson, E. H. (1968). Identity, youth, and crisis. New York: W. W. Norton. http://dx.doi.org/10.1111/0022-4537.00220

Esses, V. M., Dovidio, J. F., Jackson, L. M., \& Armstrong, T. L. (2001). Immigrants and immigration. Journal of Social Issues, 57, 389-412.

Gardner, R. C. (2004). Attitude/Motivation Test Battery. International AMPTB Research Project.

Gartner, S. L., \& Dovidio, J. F. (2000). Reducing Intergroup Bias: The Common Ingroup Identity Model. Philadelphia, PA: The Psychology Press.

Hofman, J. E. (1974). Predicting the Use of Hebrew Terms among Israeli Psychologists. International Journal of the Sociology of Language, 3, 53-65.

Ilatov, Z. Z., \& Shamai, S. (1996). Israeli students' attitudes toward children immigrants from Russia. Journal of Culture \& Society, 4, 77-93.

Jasinkaja-Lahti, I., Liebkind, K., Horenczyk, G., \& Schmitz, P. (2003). The interactive nature of acculturation: perceived discrimination, acculturation attitudes and stress among young ethnic repatriates in Finland, Israel, and Germany. International Journal of Intercultural Relations, 27, 79-97. http://dx.doi.org/10.1016/S0147-1767(02)00061-5

Kayam, O., \& Hirsch, T. (2012). Family Language Policy of the English Speaking Immigrant Community in Israel: Families with Young Children and Their FLP Planning, Management, and Outcomes. International Journal of Linguistics, 4(4), 622-635. http://dx.doi.org/10.5296/ijl.v4i4.2631

Kayam, O., \& Hirsch, T. (2012). Using Social Media Networks to Conduct Questionnaire Based Research in Social Studies Case Study: Family Language Policy. Journal of Sociological Research, 3(2), 57-67. http://dx.doi.org/10.5296/jsr.v3i2.2176

Kayam, O., \& Hirsch, T. (2013). Israel's English speaking immigrant parents' family language policy management: Language in the education domain. International Journal of Linguistics. (in Press). http://dx.doi.org/10.5296/ijl.v5i1.2680 


\section{Macrothink}

Issues in Social Science ISSN 2329-521X 2014, Vol. 2, No. 1

Lewin, B. A. (1987). Attitudinal aspects of immigrants' choice of home language. Journal of multilingual and multicultural development, 8(4), 361-378. http://dx.doi.org/10.1080/01434632.1987.9994297

Nadel, E., \& Fishman, J. A. (1977). English in Israel: A Sociolingual Study. In J. A. Fishman, R. L. Cooper, \& A. W. Conrad (Eds.), The Spread of English, Rowley, Mass.: Newbury House.

Phinney, J. S. (1990). Ethnic identity in adolescents and adults: Review of research. Psychological Bulletin, 108, 499-514. http://dx.doi.org/10.1037/0033-2909.108.3.499

Rosenthal, D. A., \& Feldman, S. S. (1992b). The relationship between parenting behavior and ethnic identity in Chinese-American and Chinese-Australian adolescents. International Journal of Psychology, 27, 19-31. http://dx.doi.org/10.1080/00207599208246863

Sam, D. L. (1992). Psychological acculturation of young visible immigrants. Migration World, 20(3), 21-24.

Sam, D. L. (1995). Acculturation attitudes among young immigrants as a function of perceived parental attitudes toward cultural change. Journal of Early Adolescence, 15(2), 238-258. http://dx.doi.org/10.1177/0272431695015002004

Van Oudenhoven, J. P., Ward, C., \& Masgoret, A., (2006). Patterns of relations between immigrant and host societies. International Journal of Intercultural Relations, 30, 637-651. http://dx.doi.org/10.1016/j.ijintrel.2006.09.001

Zemach, M., \& Wiesel, R. (1996). Adaptation of immigrants from the CIS (1990-1995) in Israel: Follow-up study \#5. Tel Aviv: Dachaf Institute (in Hebrew). 